\title{
Female clothes preference related to male sexual interest
}

\author{
ED M. EDMONDS and DELWIN D. CAHOON \\ Augusta College, Augusta, Georgia
}

\begin{abstract}
Male and female college students rated 40 pictures of women's apparel in terms of the extent to which men would be sexually aroused by women wearing the various styles of clothes. These ratings correlated .85 , indicating that females are very knowledgeable concerning the sexual impact of clothing styles upon men. A second phase of the study demonstrated that women who perceive themselves as being sexually attractive have a marked preference for those clothes judged to be most sexually exciting for men. The results are discussed with respect to possible social implications and the degree of female awareness concerning sexual cue control.
\end{abstract}

Several recent studies have concluded that men frequently misinterpret the social behavior of females as indicating sexual interest when no such message is intended. Abbey (1982), for example, reported a study in which a male and female participated in a 5-min conversation while a concealed male and female observed this interaction. The results indicated that undergraduate male actors and observers rated the female actor as being more promiscuous and seductive than she was rated by female actors and observers. Males also reported greater sexual attraction to the opposite-sex partner than did females. Furthermore, males were more likely to perceive sexual interest toward females on the part of other men than were females. The results were interpreted as indicating that men are more likely than women to view the world in sexual terms. The author interprets these findings as representing a general male bias not shared by females.

Abbey (1982) also reported a study by Zellman, Johnson, Giarusso, and Goodchilds that concluded that women are often unaware of the sexual implications of their clothing. Based upon interviews with 432 adolescents of both sexes in the Los Angeles area, it was found that males were more likely than females to interpret a lowcut top, shorts, tight jeans, or no bra as indications of sexual receptiveness.

Since males clearly do respond with varying sexual interest based upon female apparel, it seems remarkable that women should remain ignorant of the alleged "male bias." Instead, on the basis of differential social feedback, it might seem more likely that women would learn what aspects of dress and behavior are sexually alluring to men. Furthermore, for those women who are reinforced by attention from males, sexually relevant dress and mannersisms might be readily shaped in the natural environment. On the other hand, because of cultural sanctions against viewing sex as a commodity, it

The authors' mailing address is: Department of Psychology, Augusta College, Augusta, GA 30910. would be expected that social control based upon the manipulation of sexual cues would be an unacceptable concept to many females. If this were the case, direct acknowledgement and/or awareness of sexual-social control would be lacking. The tendency of males to overestimate the salience of sexual cues, therefore, may possibly be matched by a corresponding tendency for females to deny their use of sexual cues to maximize social reinforcement from males.

The present study bears upon one aspect of this more general issue and examines female awareness of the sexual impact of various types of clothes upon men, and the extent to which females who perceive themselves as sexually attractive prefer such clothes.

\section{METHOD}

\section{Subjects}

The subjects were 89 females and 44 males enrolled in two introductory psychology courses at Augusta College. No special incentive to participate in the experiment was offered. The subjects were told at the beginning of the session that sexually relevant slides would be shown and that anyone who did not wish to participate might be excused. However, all students chose to remain in the classrooms.

\section{Procedure}

A set of 40 slides featuring women wearing a variety of clothes had been prepared. The slides were based upon pictures taken from magazines that emphasize women's fashions; the clothes illustrated in the slides ranged from demure frocks to revealing swim wear. All pictures were approximately the same size and, insofar as possible, involved similar poses. The pictures were cropped at neck level in order to eliminate facial cues.

Before the slides were presented, a rating-form packet, with a cover sheet requesting sex, age, weight, and height, was distributed to each subject. To ensure anonymity, the subjects were asked specifically not to place their names on the forms.

Following completion of the personal data sheet, the subjects were instructed to turn to the next page of the packet. The following instructions were printed at the top of the page and were also read aloud by the experimenter:

I am going to show you some slides. Each slide contains a picture of clothing worn by women. Please rate the clothing 
according to how sexually arousing you believe it appears to men. Indicate your opinion by circling one of the seven numbers on each slide's scale. Note that " 1 " stands for "Least sexually arousing" and "7" stands for "Most sexually arousing."

Before you rate the clothing, I am going to show you all the slides so that you will be better able to rate each item of clothing using the sexual arousal scale. Here are the slides. DO NOT RATE THE SLIDES AT THIS TIME.

The 40 slides were then projected at the rate of $5 \mathrm{sec}$ each to provide general familiarity with the pictures. Following this preview, the slides were shown again for $15 \mathrm{sec}$ each, and the ratings from "Least sexually arousing" to "Most sexually arousing" were recorded by both males and females.

The next page of the rating form set was headed Women Only and contained the following instructions, which were also read aloud:

We are going to show you the pictures again. For each picture indicate the extent that you like and would wear the style of clothing shown in the picture. Note that " 1 " stands for "Dislike very much" and "7" stands for "Like very much."

The next step in the study was an attempt to compare judgments of female physical attractiveness for men and women, and to establish which females considered themselves to be physically attractive. A slide was prepared featuring 11 types of bare female posteriors based upon drawings prepared for Falmer International Limited, the British jeans manufacturer, and presented in a Psychology Today article by David White (1979). The instructions accompanying this presentation were as follows:

I am going to show you a drawing, derived from photos, of 11 different types of women's buttocks. These drawings were obtained from a British jeans manufacturer who wished to determine which kind of bottoms turn people on and which kind turn them off.

Please select what you believe to be the three prettiest bottoms and indicate your selections below.

The form then required a ranking of three posteriors judged to be most attractive.

Following this evaluation, both male and female subjects were requested to rank-order the three posteriors considered to be sexiest.

The last step in the rating process was restricted to females, each of whom was asked to rank the three bottoms from the set of 11 posteriors in the order of their resemblance to her own posterior. In this manner, it was possible to obtain comparisons between each subject's perception of her buttocks and the earlier ratings of "prettiness" and "sexiness."

On the basis of these ratings, the specific questions addressed by this study were as follows:

1. What is the extent of female awareness concerning the relationship between different types of feminine attire and sexual interest in the male?

2 . Is there a relationship between females' evaluation of their own posteriors in sexual terms and their preference for clothes that elicit sexual interest in males?

\section{RESULTS AND DISCUSSION}

As a partial reliability check on the procedure, the 44 males in the study were divided randomly into two groups, and their ratings of the arousal value of the 40 clothes slides were correlated. The coefficient obtained was .95 , attesting to the reliability of the measurement process.

A highly significant correlation of .85 was obtained between male and female ratings of the sexual-arousal value (to men) of the 40 items of women's clothing $[\mathrm{t}(38)=10.06, \mathrm{p}<.001]$. Furthermore, men and women expressed perfect agreement concerning the seven items of clothes judged to have the greatest arousal value. The women in this study were nearly as expert in specifying the conditions of male sexual arousal as the males themselves.

High agreement was also found between men and women concerning the relationship between "sexy" and "pretty." When the top two ratings for "sexiest" bottoms and "prettiest" bottoms were compared for each male, the extent of overlap between the two categories was found to be $95 \%$. For the females, the corresponding overlap was $92 \%$. College females, therefore, seem to equate female sexuality and attractiveness to almost the same extent as college males.

The comparison of perceived sexual attractiveness and clothes preference was obtained in the following way: For each female, the two posteriors rated "sexiest" were compared with the two posteriors selected as most representative of the subject's own buttocks. If both sets of ratings contained the same posteriors, the subject was classified as perceiving her own bottom as sexy. A discrepancy in the two sets of ratings resulted in a classification of a self-perception of nonsexy. Subjects in the "sexy-nonsexy" categories were then assessed with respect to their personal liking for the seven items of clothes judged by both men and women to have the highest sexual-arousal value. Eight of the subjects were eliminated from this phase of the study because they failed to complete all the questionnaire items. The resulting point-biserial correlation of .80 was highly significant $(\mathrm{t}=8.21, \mathrm{p}<.001)$. On the basis of this study, therefore, it seems probable that women can accurately assess the sexual impact of their clothes upon men and that women who perceive themselves as sexually attractive show a marked preference for sexually arousing clothes.

It must be emphasized that these results are correlative and do not prove cause and effect. That is, it is possible that women do not directly base their clothes preferences upon sexual considerations as such. Factors such as fashionability, for example, may be more important in clothes preference than are sexual factors. If "fashionability" for attractive women is in turn related to the enhancement of sexual cues, however, the net effect would be the same. Although the results of this study strongly suggest that college-age women do have an awareness of the sexual impact of their clothing, it does not prove that this is a direct or conscious factor when clothes are actually selected.

Most attention based upon sexual attractiveness is nonsexual, taking the form of social approval. Since 
social reinforcement is gratifying to most humans, it is scarcely surprising that attractive women should elect to maximize their attractiveness. Also, since the sexes interact reciprocally, at least partly on the basis of sexual interest, the women in this study were reflecting behavior that seems both normal and appropriate. The possibility that women frequently control sexually relevant cues in the presence of men is often denied, however. For example, in the study by Abbey (1979), cited earlier, both men and women observers rated the female actors as being more flirtatious toward their male partners than vice versa. Although this is interpreted by the author as substantiating that the term "flirtatious" implies female gender, the more parsimonious explanation may be that the females were more flirtatious, although without sexual intent. Perhaps corresponding to the male tendency to overestimate sexual cues, there is a tendency for the female to fail to acknowledge the sexual cues that she emits in the presence of males.
The discussion presented here should not be construed as applying to all males or all females. Both classes are exceedingly broad, including, at the extremes, newly born infants and very old people, with many levels of intellectual and emotional maturity at all ages. The college-age females in this study, however, seemed strikingly aware of their sexual impact upon men and preferred clothes that tended to maximize this impact. A fuller description of the specific motives and attitudes underlying this tendency must await further research.

\section{REFERENCES}

Aввеy, A. (1982). Sex differences in attributions for friendly behavior: Do males misperceive females' friendliness? Journal of Personality and Social Psychology, 42, 830-838.

White, D. (1979, July). The bottom line. Psychology Today, pp. 88-89.

(Manuscript received for publication January 18, 1984.) 